able. The depth of the fissure is unknown, but the drop in the stream bed showed a downward extent of six feet in which there was no perceptible decrease in width. The dike is parallel to the jointing in the porphyry and can be traced for over fifty feet before it pinches out. It is marked by a number of pinches and swells, giving the formation the appearance of several long, thin, connected lenses of conglomerate standing vertically in the porphyry.

The obvious explanation is that a fissure in the igneous rock has been filled by stream wash, afterwards cemented by calcareous waters, but the origin of the fissure is by no means as clear. Many of the clastic dikes hitherto described have been attributed to the squeezing up from below of fragmental material, while in those filled from above there usually has been evidence of considerable local disturbances to account for the formation of the open fissure. ${ }^{1}$ For reasons that can not be given here, but which will be given in a forthcoming paper on the district, it is fairly well established that there has been at Silverbell no recent rock movement sufficient to form open cracks in any of the rocks. It seems more probable that the dike in question represents the result of a joint plane enlarged by weathering, and filled in part by the products of this weathering and in part by sediment washed in by the stream. It is therefore a local feature, and bears no relation to the dynamics of the district, although superficially resembling clastic dykes that have been the result of distinct orogenic movements.

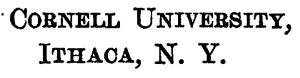

\section{NOTE REGARDING MAIZE FLOWERS}

IT may be well to make here the preliminary announcement of some results obtained in the continuation of my studies of the evolution of the "ear" of Indian corn (maize) begun some years ago. It will be recalled that I

${ }^{1}$ J. F. Newsom, Bull. Geol. Soo. Amer., Vol. 14, pp. 227-268, and M. R. Campbell, Amer. Geol., Vol. 33, pp. 135-137. published in the Popular Science Monthly for January, 1906, a paper entitled "What is an Ear of Corn?" in which I homologized the "ear" with the central spike of the ordinary "tassel," of staminate spikelets. Continuing my studies I have now found perfect flowered (hermaphrodite) spikelets in well-developed "ears" occupying the usual lateral position upon the plants. These are fully figured in a paper which is nearly ready for publication under the title of "Perfect Flowers in Maize." It is found that these are produced upon plants that differ markedly from the ordinary type of Indian corn (maize). They are shortjointed, with broad, leathery leaves, and I venture the suggestion that these plants may resemble in some degree the original form from which our common maize was derived. One of the photographs shows the remnants of an abortive second flower in the pistillate spikelet near the well-developed kernel taken from one of these perfect-flowered ears, indicating that these spikelets were once two-flowered.

\section{The UnIversity of NebrasKa}

\section{E. G. Montgomery}

\section{THE INDIANA ACADEMY OF SCIENCE}

THE twenty-sixth annual meeting of the Indiana Academy of Science was held in Indianapolis, Friday, November 25, 1910. The president of the academy, Professor P. N. Evans, chose as his subject for his annual address, "The Place of Research in the Undergraduate Schools." Forty-two regular papers were presented. Those of most general interest were as follows:

"Plants and Man-Weeds and Disease," Robert Hessler, of Logansport.

"Indiana Municipal Water Supplies," Charles Brossman, Indianapolis.

"Subterranean Drainage in the Bloomington Quadrangle," J. W. Beede, of Bloomington.

"Conservation Problems," Frederick J. Breeze, of Lafayette.

"The Properties and Reactions of Thrombin," L. J. Rettger, of Terre Haute.

"The Nature and Origin of the Fish Fauna of the Plateau of British Guiana," C. H. Eigenmann, of Bloomington.

"A Physiographic Survey of the Terre Haute Area," Charles R. Dryer, of Terre Haute.

"Paleolithic, Neolithic, Copper and Iron Ages 